\title{
CDISC SEND Specimen Spatial Organization Terminology
}

National Cancer Institute

\section{Source}

National Cancer Institute. CDISC SEND Specimen Spatial Organization Terminology. NCI

Thesaurus. Code C90001.

The terminology that includes concepts relevant to the Clinical Data Interchange

Standards Consortium (CDISC) Standard for the Exchange of Non-clinical Data (SEND)

specimen spatial organization. 